\title{
Intepretation of Employees Intelligence in Handling Machinaries Associated With Manufacturing Units
}

\author{
S. Praveen Kumar
}

\begin{abstract}
Many organisations operate with the strong belief to contribute positively to the society, economy and strong corporate work culture. This defines the level of employee engagement that transforms the organisation into a high performance genre. An organisation's culture is an essential part of business. It influences nearly every aspect of the organisation, from acquiring top talent to improving employee satisfaction, employee engagement and enhancing employee productivity, it becomes the basis of a happy workforce. A distinct corporate culture is important to the success of an Organisation. Hence to bring out the transformation in the culture it is import for the decision makers to be aware of the influencers. Good Leaders with high level of EI can drive the behaviour and positively impact people to create a successful work culture. The objective of this paper is to explore the relationship between emotional intelligence and transformational leadership and their effect on organizational culture.
\end{abstract}

Key Words: Emotional Intelligence, Organizational Culture and Transformation Leader.

\section{INTRODUCTION}

The importance of Culture in organisations has risen to newer existence inthe recent years, this has led to the transition towards globalization and competitiveness among many organizations. The significance for the concept of organizational culture has been thriving since the 1980s, numerous business articles carry issues that promote culture as the primary factorfor an organization's success and managers who are able to manage through their organization's culture have risen to the top.

The efficacy of an organization depends on its leaders, the leadership styles and their emotional literacy will surely influence the organizations, especially in the area of organisational culture. Transformation leaders are eyed as effective and positive leader's with traits of encouraging and motivating their employees towards a common goal, transformation leaders with emotional intelligence would be an added advantage for the organizations to pave the way for the development of organizational culture that emphasizes on the importance of emotional intelligence and transformational qualities.

\section{EMOTIONAL INTELLIGENCE}

Emotional intelligence (EI) is the space for cognitive ability that promotes interpersonal behaviour. The definition of Emotional intelligence according to Dr. Goleman is, "Emotional intelligence of a person is the ability to manage his feelings, so that those feelings can be expressed appropriately and effectively". According to Goleman, emotional intelligence is the largest single predictor of success in the workplace.

Research has shown that top managers in various organizations have been successful due to high level of emotional intelligence they practice and possess. Emotional Intelligence has been defined as "a set of skills that enables us to make our way in a complex world - the personal, social and survival aspects of overall intelligence, the elusive common sense and sensitivity that are essential to effective daily functioning" (Stein and Book 2011, p. 14)

\section{ORGANISATIONAL CULTURE}

The culture of an Organisation is based on the Values derived from the inherent habits of leaders, the relationship between the organisation and its environment, Emotions and the outcome of effectiveness. The culture within an organisation in the long run creates the brand identity.

The culture of an organisation can be manifested in many ways like the attitude of Leaders, styles and means of communication, innovation and cross cultural strategies, employee engagement and corporate events.

\section{TRANSFORMATIONAL LEADERSHIP}

Transformational leadership is style adapted by many inspiring personalities to embrace change and foster a strong culture based on accountability.

A Transformational Leader inspires and motivates his team. All activities are generally focused towards innovation and future growth of the organisation. Transformational leaders are citied high up in the hierarchy who are accountable for a building a strong sense of corporate culture through coaching and mentoring to their employees
Revised Manuscript Received on December 16, 2019

S Praveen Kumar, Department of Science and Humanities, Bharath Institute of Higher Education and Research, Tambaram, India 


\section{Intepretation of Employees Intelligence in Handling Machinaries Associated With Manufacturing Units}

\section{EMOTIONAL INTELLIGENCE, ORGANISATIONAL CULTURE AND TRNASFORMATIONAL LEADERS}

According to research carried out by Salovey and Mayer, Leaders with emotional intelligence understand their own emotion, influence the emotions of peers, effectively manage their emotions to seek their goal and they induce the positive emotion into their team for the greater success.

Since it is understood that leaders play a decisive role in contributing to the organisational culture it is important that these transformational leaders are emotionally intelligent to create a positive impact, Factors Influencing Culture of an Organisation include;

- The Vision and approach of the Founders and the Leaders in an Organisation.

- The myriad size of the organisation

- The Level of Operations which include National and multinational operations

- The Organisational Structure, Management style ,policies and practices within the organisation

- The leadership style and HR polices

- Domain of operations and

- The Attitude of the Managers and employees

Fgure:1 The connect between El, Organisational Culture and Transformational Leadership

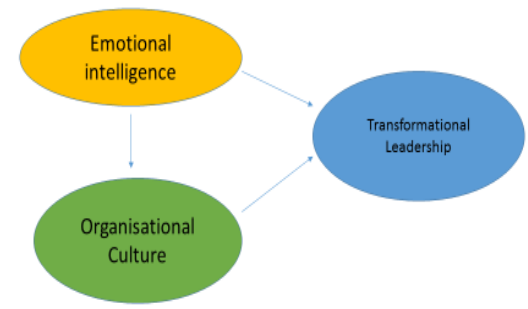

Metrics have shown that the organization that invests in the human capital have reaped good culture. An effective organisation is possible only when the Culture is backed by suitable business strategy and well formularized organisational.

Many organisations have adapted to innovative and inclusive strategies to express their Organisational Culture and they stand out as good examples for the rest to follow, to name a few Key Examples and Evidences

1. Apple- Culture to innovate and maintain secrecy regarding product development - Steve jobs.

2. Disney - Pursue the culture of the Leader Walt Disney

3. Organisation like Hp and Toyota are known for their Employee Induction programmes and employee engagement programs and many more standing examples of Organisations stand apart because of their culture and all of them have created their identity of success via their culture.

4. Recruiting style adapted by organisation especially the cross countries.

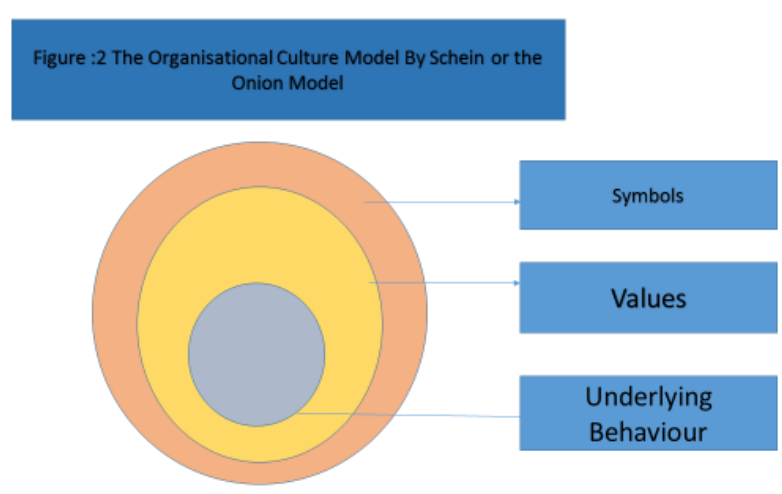

\section{THE EDGAR SCHEIN MODEL}

In the year 1980, an American professor, Edgar Schein introduced a model for defining organisational culture; the purpose was to give culture more emphasis within the organisation. Commonly known as the Onion model, the outer layer speaks about the logs, brand identity symbols adapted by the organisation which can be easily adapted and it can also be changed easily. The inner layers are the deep rooted systems which are practiced within the organisation and are difficult to change. The Leaders or the heroes are the people who operate the organisation, they form the core of the onion and they operate the system based on assumptions which suits them best. These practices are evolved through their experience and over a period of time change into unconscious practices of the system, which become deep rooted and difficult to change. Thought Edgar Schein's model is old it defines the importance of the role of Leaders and how they can bring about a change in the culture.

\section{FINDINGS AND RECOMMENDATIONS}

With reference to Organisational Culture practiced in an organisation emerges over time ,there is no perfect criterion that defines the better or the best Culture that can be adapted, the culture is purely defined by its People, the organisation's Leadersperceived by the values and systems that lead the organisations success over a period of time. The Leaders must be able to acknowledge the Cultures of the country, RegionalValues, communication styles and hiring policies. It is believed that organisations with a heathy organisational culture have accomplished a strong sense of belonging, commitment towards their work and a sense of belonging towards the organisation which contributes to the success of the organisation. The Culture of theis defined by its people so the leaders and the strategy they formulise sets the tone. So, a emotionally strong leader will contribute to a positive work culture which will pave the way to the success of the organisation

\section{REFERENCES}

[1] Baker, K., Pryor, M. and Perkins, J. (nd) Achieving graduate attributes: making the implicit explicit (Retrieved 7/5/15 from 
http://www.enhancementthemes.ac.uk

[2] Bar-On, R. (2006), The Bar-On Model of emotional-social intelligence (esi), Psicothema, 18, supl, 13-25)

[3] Barrie S.C. (2009) Understanding what we mean by the generic attributes of graduates Australia: Institute for Teaching and Learning University of $\begin{array}{lllll}\text { Sydney } & \text { (Retrieved } 28 & \text { August } & 2015 & \text { from }\end{array}$ http://www.itl.usyd.edu.au/GraduateAttributes/barriepaper.pdf

[4] Bradberry, T. and Greaves, J. (2009), Emotional Intelligence 2.0, CA: TalentSmart

[5] Caruso, D.R. (2008) Emotions and the Ability Model of Emotional Intelligence in Emmerling,

[6] R.J., Shanwal, V.K. and Mandal, M.K. (eds), Emotional Intelligence Theoretical and Cultural Perspectives, New York: Nova Science Publishers Inc.

[7] Dr. Chandra Mohan, A and Prasad, B. V. S, "Emotional Intelligence and Self Motivational Factors for Managerial Effectiveness in the Corporate World", NATIONAL MONTHLY REFEREED JOURNAL OF RESEARCH IN COMMERCE \& MANAGEMENT, VOLUME NO.1, ISSUE NO.11.

[8] Hassan Jorfi, "The impact of emotional intelligence on communication effectiveness: Focus on strategic alignment", African Journal of Marketing Management, Vol. 6(5), pp. 82-87, October, 2014.

[9] M.Suvarchala Rani, "Emotional Intelligence - A Model for Effective Leadership, Competency and Career Growth", Indian Journal of Science and Technology, Vol 8 (S4), 240-246, February 2015.

10. Vladimir, "Project Managers Emotional Intelligence - A Ticket to Success", Journal in Procedia - Social and Behavioral Sciences,74 ,274 $284,2013$.

\section{AUTHORS PROFILE}

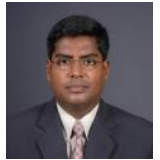

S. Praveen Kumar Department of Science and Humanities, Bharath Institute of Higher Education and Research, India 